\title{
Longevity and viability of Taenia solium eggs in the digestive system of the beetle Ammophorus rubripes
}

\author{
Duração e viabilidade de ovos de Taenia solium no sistema digestivo do besouro Ammophorus rubripes \\ Luis Antonio Gomez-Puerta ${ }^{1 *}$; Maria Teresa Lopez-Urbina ${ }^{1}$; Hector Hugo Garcia ${ }^{2}$; Armando Emiliano Gonzalez ${ }^{1}$ \\ ${ }^{1}$ School of Veterinary Medicine, Universidad Nacional Mayor de San Marcos, Lima, Peru \\ ${ }^{2}$ Department of Microbiology, School of Sciences, Universidad Peruana Cayetano Heredia, Lima, Peru
}

Received June 13, 2013

Accepted December 5, 2013

\begin{abstract}
The present study evaluated the capacity of Ammophorus rubripes beetles to carry Taenia solium eggs, in terms of duration and viability of eggs in their digestive system. One hundred beetles were distributed into five polyethylene boxes, and then they were infected with T. solium eggs. Gravid proglottids of T. solium were crushed and then mixed with cattle feces. One gram of this mixture was placed in each box for 24 hours, after which each group of beetles was transferred into a new clean box. Then, five beetles were dissected every three days. Time was strongly associated with viability $(\mathrm{r}=0.89 ; \mathrm{P}<0.001)$ and the calculated time to cero viability is 36 days. The eggs in the intestinal system of each beetle were counted and tested for viability. Taenia solium eggs were present in the beetle's digestive system for up to 39 days $\left(13^{\text {th }}\right.$ sampling day out of 20$)$, gradually reducing in numbers and viability, which was 0 on day 36 postinfection. Egg viability was around $40 \%$ up to day 24 post-infection, with a median number of eggs of 11 per beetle at this time. Dung beetles may potentially contribute towards dispersing $T$. solium eggs in endemic areas.
\end{abstract}

Keywords: Taenia solium, dung beetle, Ammophorus rubripes.

\section{Resumo}

Este estudo avaliou a duração e viabilidade de ovos de Taenia solium no sistema digestivo do besouro Ammophorus rubripes como portador dos ovos de T. solium. Cem besouros foram distribuídos em cinco caixas de polietileno, contendo um grama de fezes bovina misturada à proglotes grávidas de T. solium trituradas. Após 24 horas, cada grupo de besouros foi transferido para uma caixa limpa e, a cada três dias, cinco besouros foram dissecados para determinar a contagem e viabilidade dos ovos nos intestinos de cada besouro. Ovos de T. solium foram detectados no sistema digestivo até 39 dias (130 dia da amostragem de 20), observando-se uma redução gradativa do número e viabilidade dos ovos, até 36 dias após a infecçáo. A viabilidade dos ovos foi de $40 \%$ após 24 horas da infecção, com uma média de 11 ovos por cada besouro. Besouros coprófagos têm potencial para contribuírem na dispersão dos ovos de T. solium em áreas endêmicas.

Palavras-chave: Taenia solium, besouros coprófagos, Ammophorus rubripes.

\section{Introduction}

Dispersal of cestode eggs of the Taeniidae family can occur in various manners, resulting in different ways in which they can be ingested by the corresponding host. For example, the motility of proglottids of Taenia saginata, Taenia ovis and T. hydatigena allows the eggs to be moved away from human feces into areas where the intermediate host can eat them (LAWSON; GEMMELL, 1983; GEMMELL et al., 1987). On the other hand, Taenia solium proglottids are not motile. Therefore, the intermediate hosts

\footnotetext{
*Corresponding author: Luis Antonio Gomez-Puerta

Laboratory of Preventive Veterinary Medicine, School of Veterinary Medicine,

Universidad Nacional Mayor de San Marcos, Av. Circunvalacion 2800, San

Borja, Lima 41, Peru

e-mail: lucho92@yahoo.com
}

needs to ingest the eggs directly from the site of their deposition (GEMMELL et al., 1978).

Dispersal of T. solium eggs can occur through other mechanisms. For example, pigs eliminate a proportion of the eggs in their feces after ingesting gravid proglottids and parasite eggs from human feces. These eggs excreted by a pig can be eaten by other pigs because of their coprophagous habits, resulting in disease transmission from pig to pig (GONZALEZ et al., 2005, 2006).

Furthermore, invertebrates transport a great number of helminth eggs (PROKOPIC; MINAR et al., 1980; LAWSON; GEMMELL, 1983, 1985). Insects can carry helminth eggs from the feces and disperse them in the environment by carrying them externally on their legs, wings and body or internally, in their digestive tract 
(LAWSON; GEMMELL, 1983). Egg transmission in the insect digestive tract is more important than the transmission through its surface, because the eggs inside the digestive tract are protected from desiccation and adverse weather conditions (PROKOPIC; MINAR et al., 1980). Some scientific studies have attempted to prove the role of insects in the transmission dynamics of tapeworm eggs. Different studies conducted in Europe and North America have shown that various beetle species can carry eggs of $T$. saginata inside their digestive tract and disseminate these eggs elsewhere (BILY et al., 1978; LONC, 1980; PROKOPIC; MINAR et al., 1980). The present study evaluated the persistence and viability of $T$. solium eggs inside the digestive tract of experimentally infected Ammophorus rubripes beetles.

\section{Materials and Methods}

\section{Beetles}

One hundred Ammophorus rubripes beetles were collected directly from cattle feces on a dairy farm located in an area free from porcine cysticercosis. The beetles were separated into five polyethylene boxes $(10 \mathrm{~cm} \times 1 \mathrm{~cm})$, each containing 20 beetles that had fed on cattle feces on the farm.

\section{Taenia solium eggs and beetle infection}

Gravid proglottids of T. solium were obtained from expelled parasite material following routine treatment of tapeworm carriers at the Center for Global Health - Tumbes (Universidad Peruana Cayetano Heredia, Tumbes, Peru), and were preserved in transport media. Baseline egg viability testing (VERASTEGUI et al., 2002) demonstrated median viability of $78 \%$. The proglottids were crushed in a mortar and then mixed with cattle feces (one proglottid per $20 \mathrm{~g}$ of feces). One gram of this mixture was placed in each polyethylene box for 24 hours, after which the beetles were transferred into new clean boxes, keeping the original distribution of 20 beetles per box.

\section{Numbers of eggs in the digestive tract of the beetles over time}

Every third day after infection (day 0), one beetle from each box was sacrificed in an airtight container using chloroform (Sigma) and was then dissected under a microscope at $25 \times$ magnification to obtain the complete digestive tract as described by Miller (1961). The digestive tract was placed on a microscope slide, two to three drops of phosphate-buffered saline were added, and then a cover slip was placed over the specimen. The microscope slides were examined at $200 \times$ magnification. The egg count was carried out over the whole slide area.

\section{Preparation of oncospheres for viability evaluation}

After the diagnosis had been made and the T. solium eggs had been counted, the digestive tracts of the beetles were transferred to $2 \mathrm{ml}$ vials. Egg hatching was performed using the protocols of Laws (1968) and Stevenson (1983) with minor modifications. The digestive tract of each beetle was placed in a vial, and then $1 \mathrm{ml}$ of $0.75 \%$ sodium hypochlorite was added for 10 minutes. Then the vial was centrifuged three times in RPMI 1640 medium (Sigma) and resuspended in the same medium. The entire sediment was placed on a microscope slide, and oncospheres were counted and their viability was determined using $0.4 \%$ Trypan blue (Sigma) as an indicator of viability. Non-colored oncospheres were considered viable (Figure 1).

\section{Statistic analysis}

Linear regression analysis was performed to evaluate the effect of time over the viability percentage. Data was analyzed using STATA 10 statistical software (v10.0; StataCorp LP, College Station, TX). Differences were considered statistically significant at $\mathrm{p}$-value $\leq 0.05$

\section{Results}

Taenia solium eggs were consistently found in the digestive system of all beetles up to day 27 post-infection (p.i.), and thereafter in some of them. The median number of eggs per beetle decreased gradually up to day $39\left(13^{\text {th }}\right.$ sampling out of 20$)$, when eggs were no longer found. While two beetles had 121 and 210 eggs on days 6 and 9 p.i. respectively, the median number of eggs per beetle was fairly stable from day 3 to day 15, ranging between 21 and 40 eggs per beetle (Table 1 ).

The baseline viability of the $T$. solium oncospheres used for infection was $78 \%$. The viability of the oncospheres decreased soon after infection but maintained a level of approximately $50 \%$ or more for the initial 12 days. Oncosphere viability then decreased gradually to reach zero on day 27 p.i. (Figure 2).

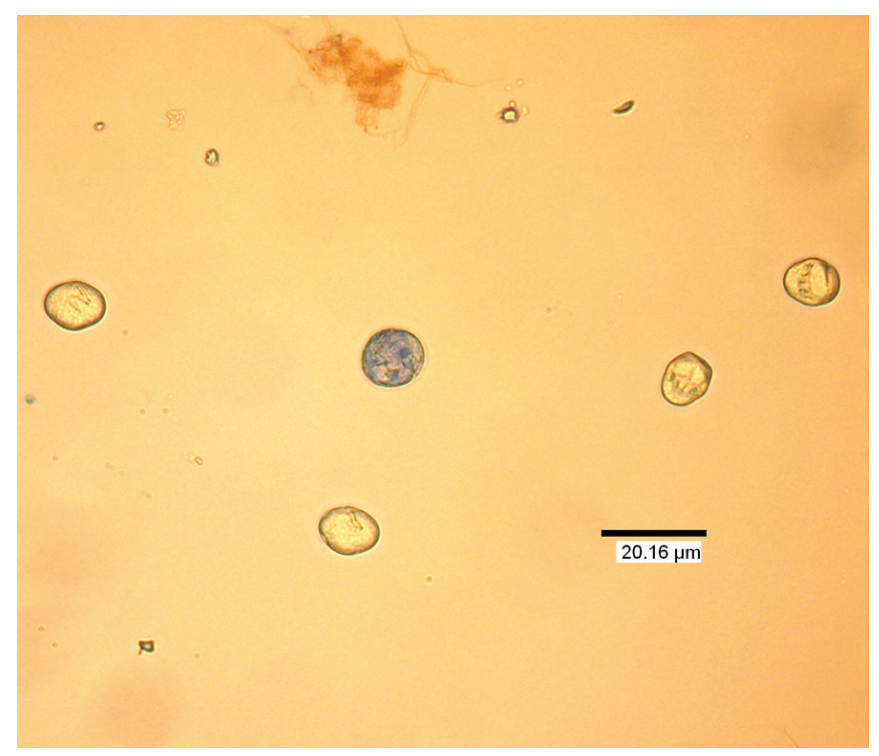

Figure 1. Oncosphere viability using Trypan blue stain. Oncospheres stained with blue are considered not viable. 
Table 1. Number of ingested and viable Taenia solium eggs found in the digestive tube of Ammophorus rubripes.

\begin{tabular}{|c|c|c|c|c|c|c|}
\hline \multirow{2}{*}{$\begin{array}{c}\text { Days } \\
\text { post-Infection }\end{array}$} & \multicolumn{3}{|c|}{ Eggs ingested } & \multicolumn{3}{|c|}{ Viable eggs } \\
\hline & Median & Maximum & Minimum & Median & Maximum & Minimum \\
\hline 3 & 28 & 61 & 11 & 21 & 49 & 9 \\
\hline 6 & 40 & 121 & 14 & 28 & 70 & 7 \\
\hline 9 & 21 & 235 & 19 & 15 & 175 & 10 \\
\hline 12 & 36 & 44 & 15 & 16 & 30 & 8 \\
\hline 15 & 41 & 68 & 7 & 19 & 30 & 4 \\
\hline 18 & 9 & 60 & 5 & 5 & 26 & 1 \\
\hline 21 & 6 & 31 & 3 & 1 & 13 & 1 \\
\hline 24 & 19 & 54 & 6 & 11 & 25 & 1 \\
\hline 27 & 4 & 10 & 1 & 0 & 2 & 0 \\
\hline 30 & 2 & 6 & 0 & 0 & 1 & 0 \\
\hline 33 & 4 & 7 & 1 & 0 & 1 & 0 \\
\hline 36 & 3 & 6 & 1 & 0 & 0 & 0 \\
\hline 39 & 0 & 0 & 0 & 0 & 0 & 0 \\
\hline - & - & - & - & - & - & - \\
\hline - & - & - & - & - & - & . \\
\hline - & - & - & - & - & - & . \\
\hline 60 & 0 & 0 & 0 & 0 & 0 & 0 \\
\hline
\end{tabular}

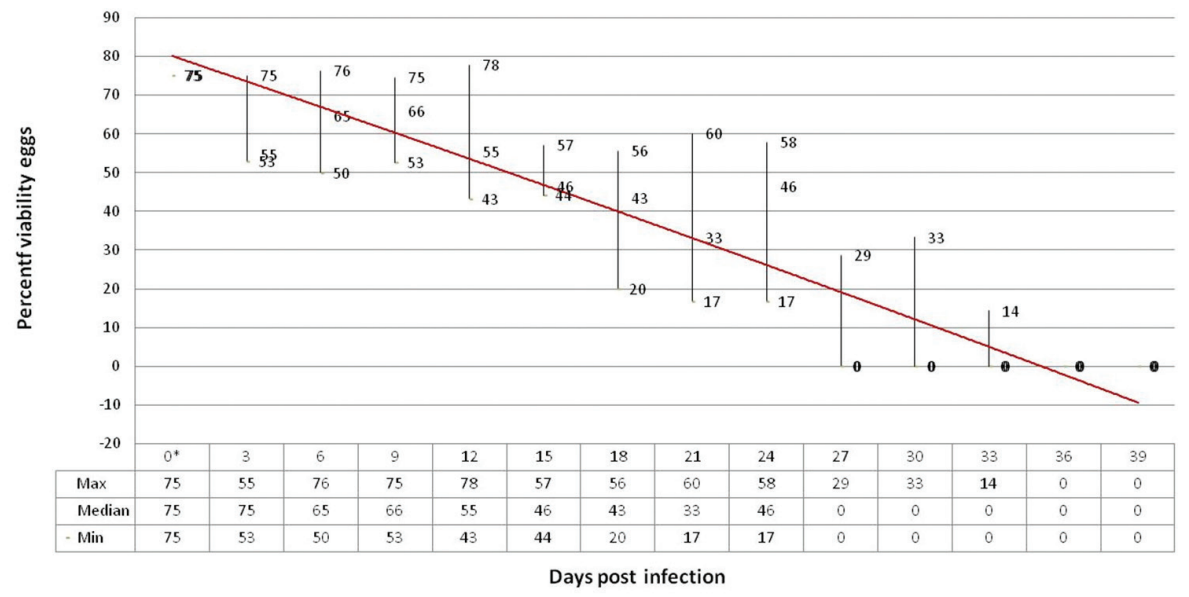

Figure 2. Taenia solium eggs viability in the digestive system of Ammophorus rubripes.

There was a strong statistical association between the interval and the viability rate $\left(\mathrm{P}<0.001, \mathrm{R}^{2}=0.7968\right)$. The regression coefficients were used to calculate that the time when viability cero is 36 days. Likewise, the calculated time until no eggs are being found in dung beetles is 45 days.

\section{Discussion}

In the present study, we observed that $A$. rubripes beetles could maintain viable $T$. solium eggs in their digestive system. A mean number of 20-40 T. solium eggs per beetle over the first 15 days p.i., with viability greater than $50 \%$, was observed in our study. The viability of the oncospheres is very important for estimating the infectivity of Taenia sp. eggs, as already stated by Coman and Rickard (1977). In our experiment, the viability was greater than $50 \%$ on the $12^{\text {th }}$ day, and then gradually decreased to zero by the $27^{\text {th }}$ day. This would indicate that the beetles may have been carrying viable eggs at least for this period.

Bily et al. (1978) infected beetles of other genera (Carabus, Pterostichus and Aphodius) by feeding them with T. saginata eggs, and observed an infection rate of 2 to $5 \%$ with an intensity of up to four eggs per beetle. In our experiment, we did not calculate the infection rate because we did not count the number of eggs per box, but the mean number of $T$. solium eggs per beetle was high (20-40 eggs per beetle for the first 15 days). In our study, the largest number of eggs was 235 eggs, found on the $9^{\text {th }}$ day. This was similar to the results of Prokopic and Minar (1980), who found one to 276 eggs of T. saginata in the digestive system of Dermestes maculatus beetles.

The viability of the oncospheres is very important for estimating the infective power of eggs of Taenia sp. (COMAN; RICKARD, 1977). In our experiment, the viability was greater than $50 \%$ on the $12^{\text {th }}$ day, and then gradually decreased to reach zero by the $27^{\text {th }}$ 
day. This would indicate that the beetles may have been carrying viable eggs for this period (27 days).

The present study demonstrates for the first time that the eggs of $T$. solium can stay in the digestive system of the beetle $A$. rubripes for a period of time, thereby maintaining their viability. Thus, dung beetles carrying small numbers of $T$. solium eggs away from the geographical locations of the scarce tapeworm carriers may contribute towards transmission of T. solium to pigs in endemic areas.

\section{Acknowledgements}

Partial support from the Fogarty International Center/NIH (training grants D43 TW008273-03 and D43 TW001140) is acknowledged. Luis A. Gomez-Puerta's PhD study is supported by the Fogarty International Center/NIH (D43 TW008273-03). Hector H. Garcia is supported by a Wellcome Trust Senior International Research Fellowship in Public Health and Tropical Medicine.

\section{References}

Bily S, Sterba J, Dyková I. Results of an artificial feeding of eggs of Taenia saginata Goeze, 1782 to various beetle species. Folia Parasitol 1978; 25(3): 257-260.

Coman BJ, Rickard MD. A comparison of in vitro and in vivo estimates of the viability of Taenia pisiformis eggs aged under controlled conditions, and their ability to immunise against a challenge infection. Int J Parasitol 1977; 7(1): 15-20. http://dx.doi.org/10.1016/00207519(77)90019-4

Gemmell MA, Johnstone PD, Boswell CC. Factors regulating tapeworm populations: dispersion patterns of Taenia hydatigena eggs on pasture. Res Vet Sci 1978; 24(3): 334-338. PMid:566948.

Gemmell MA, Lawson JR, Roberts MG. Population dynamics in echinococcosis and cysticercosis: evaluation of the biological parameters of Taenia hydatigena and T. ovis and comparison with those of Echinococcus granulosus. Parasitology 1987; 94 (Pt 1): 161-180. PMid:3822513. http:// dx.doi.org/10.1017/S0031182000053543

Gonzalez AE, López-Urbina T, Tsang BY, Gavidia CM, Garcia HH, Silva $\mathrm{ME}$, et al. Short report: secondary transmission in porcine cysticercosis: description and their potential implications for control sustainability. Am J Trop Med Hyg 2005; 73(3): 501-503. PMid:16172471.

Gonzalez AE, López-Urbina T, Tsang B, Gavidia CM, Garcia HH, Silva ME, et al. Transmission dynamics of Taenia solium and potential for pig-to-pig transmission. Parasitol Int 2006; 55 (Suppl): S131-135. PMid:16352459. http://dx.doi.org/10.1016/j.parint.2005.11.021

Laws GF. The hatching of taeniid eggs. Exp Parasitol 1968; 23(1): 1-10. http://dx.doi.org/10.1016/0014-4894(68)90038-6

Lawson JR, Gemmell MA. Hydatidosis and cysticercosis: the dynamics of transmission. Adv Parasitol 1983; 22: 261-308. http://dx.doi. org/10.1016/S0065-308X(08)60464-9

Lawson JR, Gemmell MA. The potential role of blowflies in the transmission of taeniid tapeworm eggs. Parasitology 1985; 91 (Pt 1): 129143. PMid:4041023. http://dx.doi.org/10.1017/S0031182000056572

Lonc E. The possible role of the soil fauna in the epizootiology of cysticercosis in cattle. II. Dung beetles - a biotic factor in the transmission of Taenia saginata eggs. Angew Parasitol 1980; 21(3): 139-144. PMid:7447064.

Miller A. The mouth parts and digestive tract of adult dung beetles (Coleoptera: Scarabaeidae), with reference to the ingestion of helminth eggs. J Parasitol 1961; 47(5): 735-744. PMid:14473936. http://dx.doi. org/10.2307/3275463

Prokopic J, Minar J. Dermestes maculatus de Geer, 1774 (Coleoptera, Dermestidae) as potential distributor of Taenia saginata Goeze, 1782 eggs. Folia Parasitol 1980; 27(1): 37-38.

Stevenson P. Observations on the hatching and activation of fresh Taenia saginata eggs. Ann Trop Med Parasitol 1983; 77(4): 399-404. PMid:6685462.

Verastegui M, Gilman RH, Gonzales A, Garcia HH, Gavidia C, Falcon $\mathrm{N}$, et al. Taenia solium oncosphere antigens induce immunity in pigs against experimental cysticercosis. Vet Parasitol 2002; 108(1): 49-62. http://dx.doi.org/10.1016/S0304-4017(02)00182-6 